OPEN ACCESS

Edited by:

Michelle L. Hall,

University of Melbourne, Australia

Reviewed by:

Gisela - Kaplan,

University of New England and University of Queensland, Australia

Richard Anthony Peters,

La Trobe University, Australia

*Correspondence:

Manfred Gahr

gahr@orn.mpg.de

Specialty section:

This article was submitted to Behavioral and Evolutionary Ecology,

a section of the journal

Frontiers in Ecology and Evolution

Received: 17 June 2015

Accepted: 28 September 2015 Published: 14 October 2015

Citation:

Lobato M, Vellema M, Gahr C, Leitão A, de Lima SMA, Geberzahn N and Gahr M (2015) Mismatch in sexual dimorphism of developing song and song control system in blue-capped cordon-bleus, a songbird species with singing females and males. Front. Ecol. Evol. 3:117. doi: 10.3389/fevo.2015.00117

\section{Mismatch in sexual dimorphism of developing song and song control system in blue-capped cordon-bleus, a songbird species with singing females and males}

\author{
Muriele Lobato ${ }^{1,2}$, Michiel Vellema ${ }^{1}$, Christoph Gahr ${ }^{1}$, Albertine Leitão ${ }^{1}$, \\ Silene M. A. de Lima $^{3}$, Nicole Geberzahn ${ }^{1}$ and Manfred Gahr ${ }^{\text {* }}$ \\ ' Department of Behavioural Neurobiology, Max Planck Institute for Ornithology, Max Planck Society, Seewiesen, Germany, \\ ${ }^{2}$ Department of Neuroscience and Behavior, Institute of Psychology, University of São Paulo, São Paulo, Brazil, ${ }^{3}$ Department \\ of Physiology, Federal University of Para, Belem, Brazil
}

Brain song control regions of adult passerine birds are sexually dimorphic in species such as the zebra finch (Taeniopygia guttata) in which males sing whereas females do not. In many tropical bird species, however, females sing as well. Here we study for the first time the ontogeny of the song control system and the song in a species in which both male and female sing regularly. In blue-capped cordon-bleus (Uraeginthus cyanocephalus), a distant relative of the zebra finch, both males and females start singing at around 30-40 day post-hatching (dph). First we quantified that sex-specific differences in song features emerged only in adulthood, after $250 \mathrm{dph}$ of age: Adult females sang complex songs, which were slightly shorter and contained fewer syllables as compared to the males. Second, the development of forebrain song control regions HVC (proper name) and RA (nucleus robustus arcopallii) of blue-capped cordon-bleus was quantified in both sexes at 20,30, 50, 100, 150, $250 \mathrm{dph}$ as well as in old adults. The volume and neuron numbers of the HVC and RA were sexually dimorphic throughout the entire development and remained sexually dimorphic in adulthood. Since singing developed in a non sex-specific way until $250 \mathrm{dph}$, neural sex differences to a large extent precede the behaviorally (song) sex differences. This suggests that these neuroanatomical sex differences are not causally related to the sexual differentiation of song patterns in this species.

Keywords: song system, song development, female songbird, male songbird, sexual dimorphism

\section{INTRODUCTION}

A frequently used argument to suggest that female songbirds are not capable of singing or sing only simple songs is that the neuroanatomy of the forebrain song control areas (collectively called the song system) is sexually dimorphic (Nottebohm and Arnold, 1976; DeVoogd and Nottebohm, 1981; Brenowitz and Arnold, 1986; DeVoogd et al., 1993; Gahr et al., 1998; MacDougall-Shackelton and Ball, 1999). In particular, song control areas such as HVC (letter based name) and RA (nucleus robustus archopallii) are much smaller and contain much fewer neurons in the adult 
female than in the adult males of all songbird species studied so far (Gurney, 1981; Konishi and Akutagawa, 1985; Gahr et al., 1998, 2008; Jawor and MacDougall-Shackleton, 2008; Schwabl et al., 2015). The HVC of the descending song production pathway of the song system is a sensorimotor integration area implicated in controlling the temporal dynamics of adult song and the motor-cortical RA controls the temporal-spectral details of the sounds (Yu and Margoliash, 1996; Hahnloser et al., 2002; Amador et al., 2013). The prime example of this sexual dimorphism of the song control system and singing is the zebra finch, in which stark neuroanatomical sex differences correlate with the lack of singing of adult females (Nottebohm and Arnold, 1976), even after testosterone treatment, a paradigm that induces singing in males of all species tested (for review Gahr, 2014). This neuroanatomical sex-difference of zebra finches emerges during ontogeny due to genetic and endocrine mechanisms (Gurney and Konishi, 1980; Wade and Arnold, 1996; Gahr and Metzdorf, 1999; Holloway and Clayton, 2001; Agate et al., 2003). In particular, the strong increase in sex differences of song control areas around the time when first song precursors are uttered by male zebra finches is thought to reflect the song development in males and the lack of song capacity of females (Konishi and Akutagawa, 1985). Likewise, in the canary (Serinus canaria), the other songbird species in which the development of the song system has been studied in detail, the neuroanatomy of the song system diverges strongly between males and females during ontogeny (Gahr et al., 1997). In adulthood, female canaries sing only occasionally and if at all, generally with few unstructured songs compared to adult males (Pesch and Güttinger, 1985). Female canary song can be activated by testosterone (e.g., Shoemaker, 1939; Hartley and Suthers, 1990; Hartog et al., 2009). This potential to sing correlates with the differentiation of their song control areas, which is relatively smaller as compared to canary males but relatively larger as compared to female zebra finches (Nottebohm and Arnold, 1976; Nottebohm, 1980).

However, these observations of sexually dimorphic song system differentiation are in strong contrast with the report that female singing is the rule but not the exception among songbird species (for reviews: Slater and Mann, 2004; Riebel et al., 2005; Garamszegi et al., 2006; Gahr, 2014; Odom et al., 2014). Previously, it was thought that females of only some species sing (e.g., Beletsky, 1983; Gahr and Güttinger, 1985; Hoelzel, 1986; Langmore et al., 1996; Yamaguchi, 2001). One reason for this discrepancy might be that song system development was never studied in a species in which females sing regularly. To this end, we studied both the song system development and the song development in a songbird species, the blue-capped cordon-blue (Uraeginthus cyanocephalus) in which males and females sing frequently both during ontogeny and in adulthood (Geberzahn and Gahr, 2011, 2013). Previous studies showed that male and female cordon-bleus learn parts of their song from both adult male and female tutors (Geberzahn and Gahr, 2013), with the adult female song being slightly shorter and less diversified than the male song (Geberzahn and Gahr, 2011). Here we quantify the song development of female and male cordon-bleus from juvenile age until adulthood, focusing on song parameters that were indicated previously to differ between adult males and females. In zebra finches song development ends with reproductive maturation at around 100 days posthatching (dph) (Immelmann, 1969). Since reproductive activities of cordon-bleus start around 6-8 month (i.e., about $250 \mathrm{dph}$ ) we analyzed the song development till $250 \mathrm{dph}$ (young adults) in detail. This was paralleled with the study of the developing song system neuroanatomy, in particular the volume of HVC and RA as well as their respective neuron numbers. Thus, our integrative study of the song system and song development of male and female cordon bleus should inform about the interrelationship between the neural and the behaviorally song phenotype during ontogeny.

\section{MATERIALS AND METHODS}

\section{Animals}

Blue-capped cordon-bleus (Uraeginthus cyanocephalus) originated from the breeding colony of the Max-Planck Institute for Ornithology in Seewiesen, Germany. Birds were kept on a 14:10 light:dark schedule (lights on 07:00-21:00 Central European time) at $22^{\circ} \mathrm{C}$ and ca. $50 \%$ humidity and received water and food ad libitum. From nutritional independence onwards, birds were kept in small social groups in cages till $250 \mathrm{dph}$. Therefore, juveniles experienced a normal social environment between hatching and $250 \mathrm{dph}$. Afterwards, birds were moved to same sex aviaries until they were paired and given the opportunity to breed. Adults used in this study were paired, and in breeding condition at recording or when sacrificed for neuroanatomical analysis. These adults were about 4-5 years old (mean \pm SD, minimum: males: $1642 \pm 194,1220$ days; females: $1560 \pm 221,1395$ days). All experimental procedures were conducted in accordance with German National Laws and approved by the Government of Upper Bavaria.

The study of song development was conducted with a cohort of 10 males and 10 females. Juveniles were recorded around 50, 100,150 , and $250 \mathrm{dph}$ as well as at the age of about $4-5$ years. The neuroanatomical study was conducted with a second cohort of blue-capped cordon-bleus. We included the following agegroups: $20 \mathrm{dph}$ ( $n=6$ males and $n=7$ females), $30 \mathrm{dph}(n=5$ males and $n=5$ females), $50 \mathrm{dph}$ ( $n=5$ males and $n=5$ females), $100 \mathrm{dph}$ ( $n=5$ males and $n=5$ females), $150 \mathrm{dph}$ ( $n=4$ males and $n=4$ females), $250 \mathrm{dph}(n=3$ males and $n=3$ females), adults ( $n=7$ males and $n=7$ females). The HVC volume of one $20 \mathrm{dph}$ female could not be analyzed due to damage of the brain surface.

\section{Song Recording and Analysis}

In order to obtain song that can be traced back unequivocally to a given subject, each bird was transferred temporarily to a soundattenuating chamber where song recordings were made following procedures described in Geberzahn and Gahr (2011) using Sound Analysis Pro (SAP) software (Version 2.062) at a sampling rate of $44 \mathrm{kHz}$ and 16-bit resolution (Tchernichovski et al., 2004; freely available at http://soundanalysispro.com). Thus, we recorded so-called undirected songs.

For analysis, we considered the first 50 song-like vocalizations that a subject produced after being moved to the recording 
chamber. Then, the following parameters, previously found to be sexually dimorphic in adult blue-capped cordon-bleus (Geberzahn and Gahr, 2011) were measured: the song duration, the syllable repertoire and the coefficient of variation $(\mathrm{CV}=$ $\mathrm{SD} /$ mean) of pitch goodness. The latter is described as the harmonicity of the sound and its $\mathrm{CV}$ indicates the degree of stereotypy of the harmonicity of a syllable. Songs were defined as sequence of at least three different syllables with pauses shorter than $600 \mathrm{~ms}$. For each song, syllables were automatically delineated using a constant threshold for amplitude $(23 \mathrm{~dB})$ and entropy $(-2.1)$ in the features batch window of SAP as described previously (Geberzahn and Gahr, 2011). In a next step, we printed images of spectral derivatives using SAP. Based on these images and the automatic delineation of syllables we visually compared song-like renditions of a given subject and labeled the same syllables with the same number according to their overall spectral-temporal appearance. This allowed us to determine the repertoire size of syllable types for each subject. Bluecapped cordon-bleus usually start a song with a variable number of introductory syllables, which were labeled as introductory syllables and not further categorized. We excluded introductory syllables from all further analysis.

The features batch procedure of SAP provided us with parameter tables for all syllables and we manually added a column with the "syllable repertoire" that resulted from visual inspection (see above). From these parameter tables we extracted the pitch goodness (mean, SD and $\mathrm{CV}$ ). We calculated the coefficient of variation $(\mathrm{CV}=\mathrm{SD} /$ mean $)$ of pitch goodness of the four most frequent syllables similar to previous works (Geberzahn and Gahr, 2011). For those syllables we selected the first 20 renditions that occurred in the analyzed songs. For betweensubjects comparisons, we chose the $\mathrm{CV}$ for the syllable with the lowest $\mathrm{CV}$ for each subject, i.e., the syllable with the lowest variability from rendition to rendition (minimum $\mathrm{CV}$ of pitch goodness per subject).

\section{Histology}

When the birds of the neuroanatomical cohort reached the ages of interest for this study (see above), they were decapitated, brains were extracted, immediately frozen in dry ice and then stored at $-80^{\circ} \mathrm{C}$ until sectioning. The frozen brains (right hemisphere only) were cut on a cryostat (JUNG CM 3000 LEICA) into $20 \mu \mathrm{m}$ sagittal sections and mounted onto Fisher Superfrost Plus slides. Sections were mounted onto five different sets of slides so that adjacent sections could be analyzed by different methods. After drying overnight, one series of sections (i.e., every fifth slide) was rehydrated, Nissl-stained with $0.1 \%$ Thionin (Sigma), dehydrated, immersed in xylene and cover-slipped with Rotihistokit II mounting medium. The other series of sections were stored at $-80^{\circ} \mathrm{C}$ until use. We performed the measurements of the Nissl-stained HVC and RA areas (unilateral), delineated based on their cytoarchitecture, using the built-in cursor and measurement tools in Image J software (NHI, National Health Institute, USA). All brains were coded so that the delineations made by the observers were blind to the sex and age of the sections they measured. The RA and HVC volume, respectively, was calculated by summing the areas, multiplied by section thickness, and multiplied by 5 (sampling interval).

\section{Immunohistochemistry}

In order to estimate the number of neurons in HVC and RA of $20,100 \mathrm{dph}$, and adult males and females, we performed immunohistochemistry with antibodies against the neuronspecific RNA-binding protein $\mathrm{HuC} / \mathrm{D}$ (mouse monoclonal, clone 16A11; Molecular Probes, Eugene, OR). This antibody has previously been successfully used to label neurons in a broad range of species including songbirds (e.g., Marusich et al., 1994; Barami et al., 1995; Vellema et al., 2010), and has been shown to recognize a $40-\mathrm{kDa}$ band on Western blots of extracts of human neurons, as well as mouse and avian brains (Marusich et al., 1994).

We immunostained one series of slides of each brain, i.e., every fifth section. After defrosting and drying, sections were fixed for $40 \mathrm{~min}$ in a $4 \%$ formaldehyde solution and then washed one time in phosphate-buffered saline (PBS) and three times in PBS containing $0.1 \%$ Triton X-100 (PBT) for 5 min each on a rotating shaker. Following that, the sections were incubated overnight at room temperature in $\mathrm{PBT}$, containing $0.02 \% \mathrm{NaN}_{3}, 10 \%$ horse serum (AbD Serotec, Oxford, UK), and primary antibodies against HUC/D $(2.5 \mu \mathrm{g} / \mathrm{ml})$. After three washes in PBT, sections were incubated in Alexa Fluor 555conjugated donkey anti-mouse secondary antibodies (1:500; Molecular probes) for $1 \mathrm{~h}$ at room temperature. After another two PBT rinses, brain sections were DAPI stained for $5 \mathrm{~min}$, washed in PBT, and embedded in Vectashield (Vector Laboratories, Burlingame, CA) to prevent photo bleaching and cover slipped. The slides were stored horizontally at $4^{\circ} \mathrm{C}$ until microscope analysis.

\section{Neuron Quantification}

Brain sections were examined with a Leica DM6000B digital fluorescence microscope (Leica Microsystems) equipped with a Leica DFC420 5 megapixel CCD digital color camera. DAPI and $\mathrm{Cy} 3$ filter cubes were used to visualize DAPI and the Alexa555 antibody, respectively. The resulting photomicrographs were merged and adjusted for color, brightness and contrast with Photoshop CS2 (Adobe Systems Inc., San Jose, CA) to create multicolor images.

The number of $\mathrm{Hu}$-positive cells in HVC and RA were manually counted under the microscope in three randomly selected brain sections from each bird. A counting grid was projected onto HVC and RA, and three random counting frames of $0.01 \mu \mathrm{m}^{2}$ were chosen for each brain section to estimate the neuron density in the areas of interest. The $\mathrm{Hu}$-positive cell counts were performed using a $20 \times$ magnification and cells were included if the nuclei of Hu-labeled cells were located inside the counting frame, including cells that traverse the upper and right border, but excluding the cells that traverse the lower and left border of the counting frame. Additionally, to minimize cell count overestimation due to split cells on the counting plane, only cells of which the entire nucleus could be brought in focus within the $20-\mu \mathrm{m} \mathrm{z}$-stack were included in the counts. Total neuron numbers for HVC and RA were obtained 
by multiplying the neuron density estimates with the obtained volume measurements from the Nissl-stains.

\section{Statistical Analyses}

We performed all statistical analyses with the JMP v. 10.0 software (2012, SAS Institute Inc.). To examine differences between song control regions (HVC and RA) across age- and sex-classes we applied ANOVAs with age and sex as independent variables using a general Linear Model procedure in separate data sets for HVC volume, HVC neuron numbers, RA volume and RA neuron numbers. RA data were log transformed. For song development, we used a "split plot design" as the basis for a "repeated measures across time design" to test for the differences across time and between sexes. For this, song duration, syllables repertoire and coefficient of variation of pitch goodness were used as dependent variables (log transformed). The effect of sex (male or female) is tested with respect to the variation from bird to bird. The within subject effect ("age" effect) is tested with respect to the variation from age to age of the same bird. The within bird variability-reflected in the residual error captured with sex nested within bird [bird (sex)]-was an added effect to the model and assigned as random attribute. For the neuroanatomical development and the song development, after an overall $F$-test showed significance, we used a Tukey's post-hoc test with $\alpha=0.05$ to evaluate differences between specific means. Data are given as mean \pm SEM.

\section{RESULTS}

\section{Song Development}

Juvenile males and females started to utter their first song-like vocalizations, so-called sub-songs around 30-40 dph (males: 32 $\pm 4 \mathrm{dph}$; females $31 \pm 5 \mathrm{dph}$ ). All animals, males and females, developed the typical song of blue-capped cordon-bleus with an increased pitch of syllables that are uttered toward the end of the song (Figures 1A,F; Geberzahn and Gahr, 2011). This is best seen when comparing the pitch of the first and the last syllable of a given song and was already obvious at $50 \mathrm{dph}$ in some songs (Figure 1J). In the following we focus on song duration, syllable repertoires and the $\mathrm{CV}$ of pitch goodness. As detailed below, in general, male and female songs were similar during development, even when they differed in adults.

We found a significant effect of age on song duration $\left[F_{(4,64.65)}=9.998, p<0.0001\right]$. However, song duration of blue-capped cordon-bleus was sexually dimorphic only in adults (Figures 1, 2A; males $2497 \pm 147 \mathrm{~ms}$; females $1750 \pm$ $175 \mathrm{~ms}$; post-hoc: $p=0.0034)$. This sexual dimorphism emerged due to the reduction in song duration in females during late ontogeny resp. early adulthood (i.e., after $250 \mathrm{dph}$ ) (post-hoc 250 dph vs. adulthood: $p=0.0076$ ) while song duration of males did not change significantly after $250 \mathrm{dph}$ (post-hoc $250 \mathrm{dph}$ vs. adulthood: $p=0.5591$ ). Song duration of $100 \mathrm{dph}$ females $(2842 \pm 266 \mathrm{~ms})$ did not differ from that of $250 \mathrm{dph}$ females but differed significantly from that of adult females (posthoc: $p=0.0002$ ) (Figure 2A). This was not the case for
$100 \mathrm{dph}$ males (post-hoc $100 \mathrm{dph}$ vs. adulthood; $p=0.07$ ) (Figure 2A).

Cumulative curves of new syllable types plotted against the number of syllables analyzed were visually checked (e.g., Leitner et al., 2001; Geberzahn and Hultsch, 2003). The curves only reached an asymptote in adults, 250 and $150 \mathrm{dph}$ birds, indicating that the amount of songs sampled was sufficient to cover the syllable repertoire. At $100 \mathrm{dph}$, the curve reached only saturation if we omitted the $15 \%$ of syllables that were not uttered a second time in the analyzed songs. Thus, the repertoire of 100 day old males and females might be higher than that reported in Figure 2B (see also Figure 1). At $50 \mathrm{dph}$, the syllable repertoire was not measurable due to the fact that the syllables were very variable and could not be assigned to syllable types (Figures 1E,J). Since the analysis of additional singing events of the 50-day birds did still not allow us assigning syllables to syllable types, we did not further pursue the analysis of the repertoire at this age.

For syllable repertoire, we found an effect of age $\left[F_{(3,42.15)}=\right.$ 82.25, $p<0.0001]$ and an interaction between sex and age $\left[F_{(3,42.15)}=5.65, p=0.0024\right]$. In males, syllable repertoire size dropped significantly from 100 to $150 \mathrm{dph}$ (post-hoc: $p=0.0452$ ), from 150 to $250 \mathrm{dph}$ (post-hoc: $p=0.0003$ ) but not between $250 \mathrm{dph}$ and adulthood (post-hoc: $p=0.08$ ) (Figures 1, 2B). In females, syllable repertoires decreased significantly between 150 and $250 \mathrm{dph}$, and between $250 \mathrm{dph}$ and adulthood (both post-hoc tests: $p<0.001)$. Syllable repertoire sizes differed significantly between males and females only at adulthood (males $=18.1 \pm$ 1.4 syllables; females $=10.9 \pm 1.3$ syllables; post-hoc $p=0.001$ ) (Figures 2B, 1). This was due to a stronger reduction of syllable numbers in females as compared to males, which might be related to the sex-specific song duration of adults.

Despite the reduction of overt syllables of females after $250 \mathrm{dph}$, both sexes integrated considerable numbers of new syllables (i.e., syllables not uttered before) in their repertoire between $250 \mathrm{dph}$ (Figures 1B,G) and adulthood (Figures 1A,F). Thus, blue-capped cordon-bleus have a very long sensorimotor learning period, much longer than that of zebra finches that last about till 120 after hatching (Immelmann, 1969). In addition, since our birds were moved to aviaries after $250 \mathrm{dph}$ and thus exposed to conspecifics not heard before, cordon-bleus might have a much longer sensory song learning period than zebra finches that last about till 70 after hatching (Immelmann, 1969). Since this extended period of song learning and plasticity was unexpected, song development of young adult cordonbleus (after $250 \mathrm{dph}$ ) was not studied in detail (this study and Geberzahn and Gahr, 2013) and we do not know yet till which age cordon-bleus are able to modify their songs.

We measured the CV of pitch goodness only of 150, $250 \mathrm{dph}$, and adult males and females, due to the problem of determining the syllable repertoires of earlier ages ( 50 and $100 \mathrm{dph}$, see above). We found an effect of age on the CV of pitch of goodness $\left[F_{(2,25.86)}=58.63, p<0.0001\right] . \mathrm{CV}$ of pitch goodness decreased during ontogeny in both sexes i.e., syllables' harmonicity became more stereotyped with age but significantly only after $250 \mathrm{dph}$ (post-hoc $250 \mathrm{dph}$ vs. adulthood: $p<0.0001$; Figure 2C). However, we neither found an effect of sex in the development 

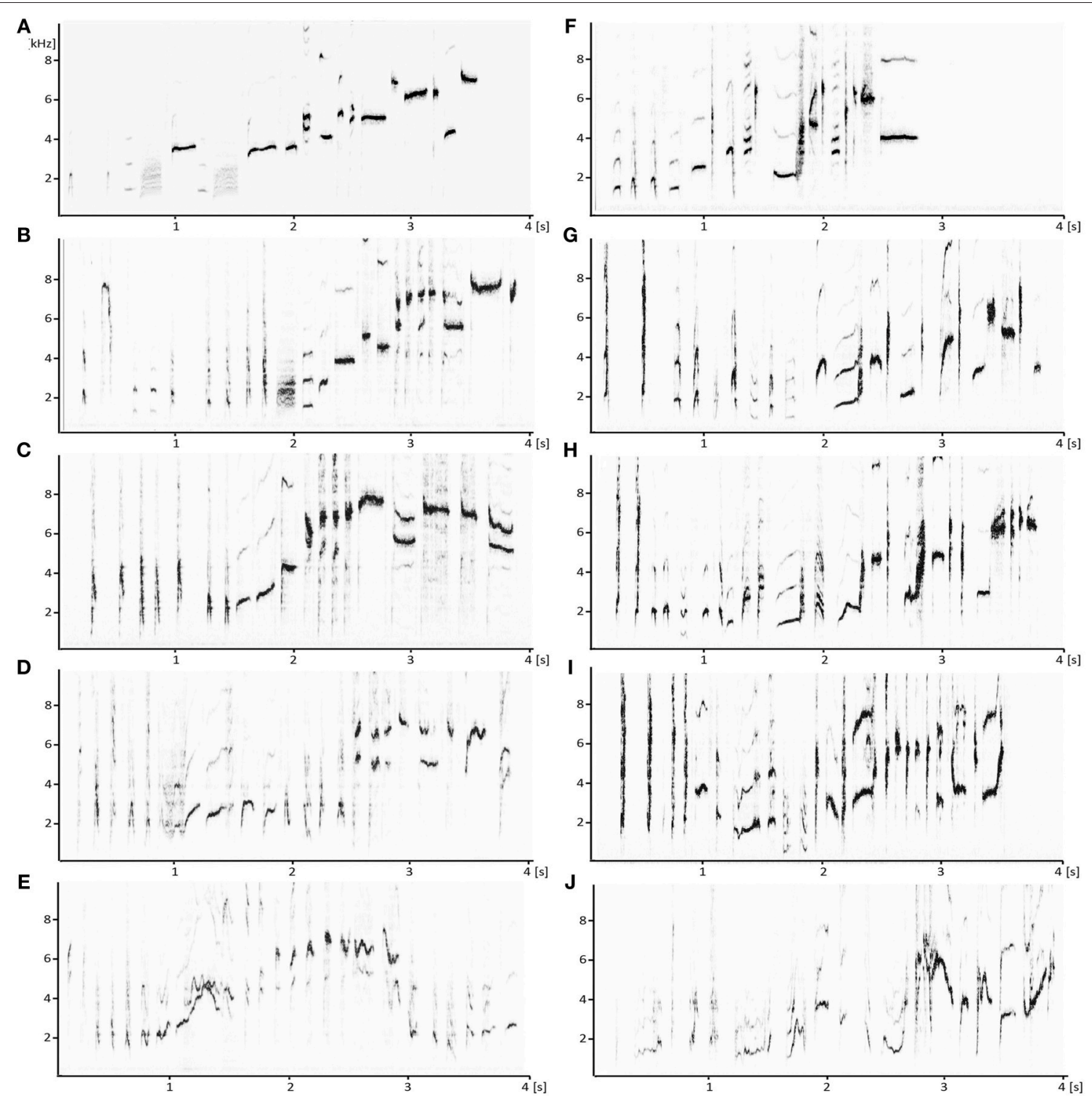

FIGURE 1 | Song development of a male (A-E) and a female (F-J) blue-capped cordon-bleu. Shown are sonograms of songs uttered at 50 (E,J), 100 (D,I), $150(\mathbf{C}, \mathbf{H}), 250 \mathrm{dph}(\mathbf{B}, \mathbf{G})$, and in adulthood (A,F). Note that songs of the female and male change considerably even after $250 \mathrm{dph}$, i.e., in adulthood.

of CV of pitch goodness $\left[F_{(1,42.39)}=0.0467, p=0.83\right]$ nor an interaction between sex and age $\left[F_{(2,25.86)}=0.6449, p=\right.$ 0.53 ]. Therefore, $\mathrm{CV}$ of pitch goodness did not differ significantly between sexes in difference to a previous study (Geberzahn and Gahr, 2011). The adult cordon-bleus of the present study were 4-5 years old and as such somewhat older than those studied previously (mean \pm SD, minimum: females: $860 \pm 226,534$ days; males: $915 \pm 228$, 578 days) (Geberzahn and Gahr, 2011). Thus, one possible explanation for this discrepancy between studies is that females change their harmonicity during adult life. Alternatively, stereotypy of harmonicity might strongly depend on the composition of the syllable repertoires between cohorts of cordon-bleus. In consequence of these contradictory results, we shall not further discuss potential sex differences in harmonicity.
In summary, song development (song duration, syllable repertoire size) of males and females was not sex-specific during most part of their ontogeny (till $250 \mathrm{dph}$ ), i.e., sex differences in song patterning emerged only during adulthood in this species. Reproductive activity starts around 6-8 month (i.e., about $250 \mathrm{dph}$ ) in cordon-bleus.

\section{Development of the Volume of the Song Control Regions HVC and RA}

HVC and RA volumes of males and females changed during development [HVC: $F_{(13,56)}=18.87, p<0.0001$; RA: $F_{(13,57)}=$ 24.37, $p<0.0001$; Figures 3, 4, 5A,C]. For both nuclei, there was a significant effect of age [HVC: $F_{(6,56)}=16.91, p<0.001$; RA: $\left.F_{(6,57)}=19.98, p<0.0001\right]$ and of sex [HVC: $F_{(1,56)}=$ 


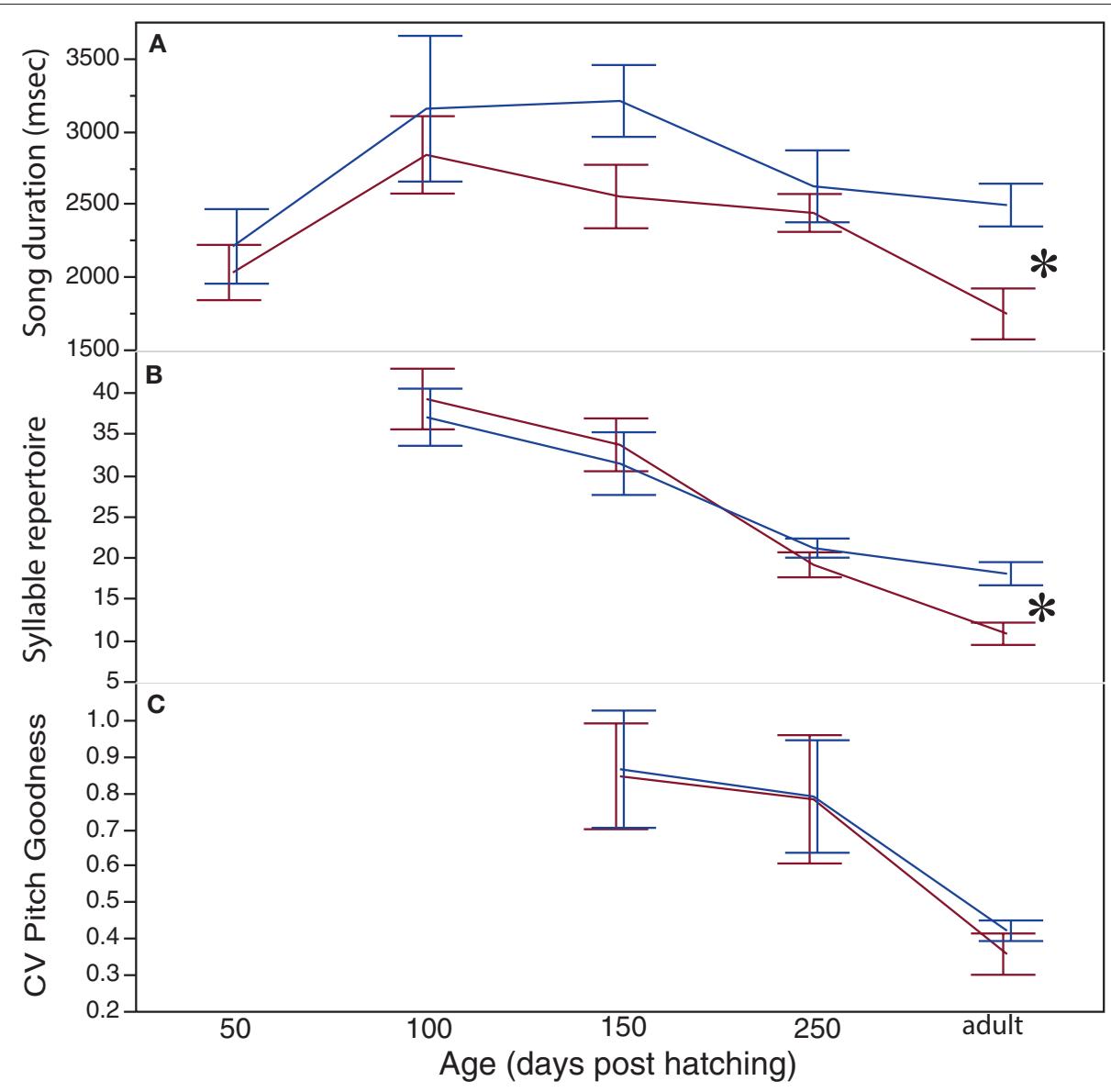

FIGURE 2 | Sexually dimorphic development of song pattern of blue-capped cordon-bleus. Depicted are the developments of song duration (A), syllable repertoire size (B), and of the harmonicity (CV of pitch goodness) (C). Note that song duration and syllable repertoire size develop similar in males (blue lines) and in females (red lines) till 250 days of age and become sexually dimorphic $\left({ }^{*} P<0.05\right)$ in adulthood. Data are presented as mean \pm 1 SE.

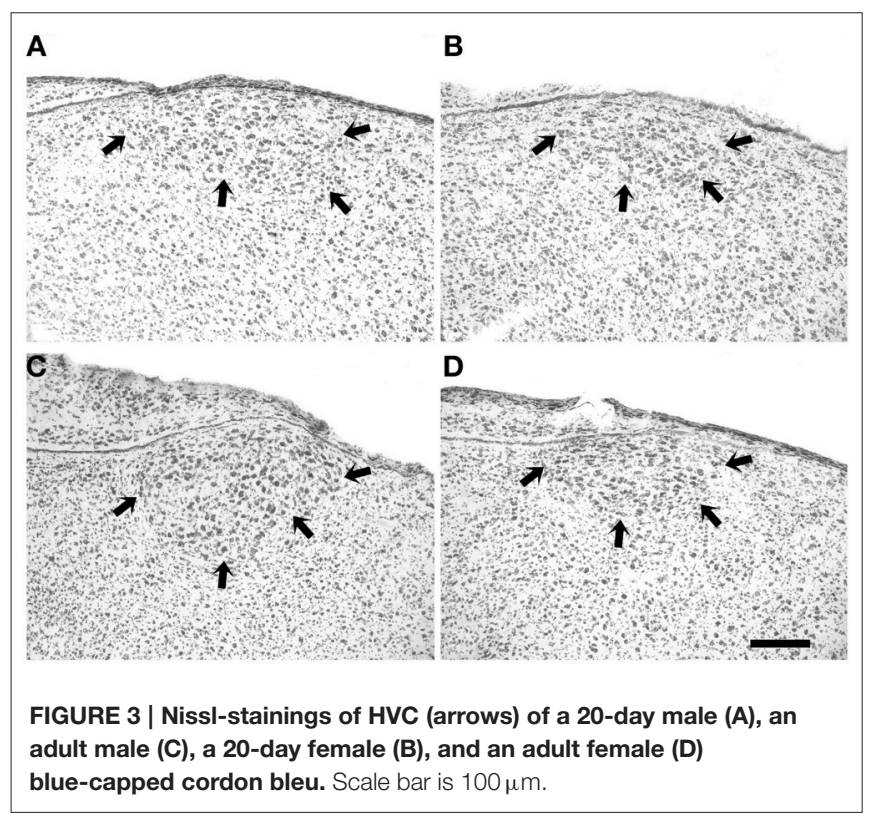

16.20, $p=0.0002$; RA: $\left.F_{(1,57)}=14.83, p=0.0003\right]$. Further, both nuclei changed similarly in males and females, i.e., there was no interaction between age and sex [HVC: $F_{(6,56)}=1.05$, $p=0.4041$; RA: $\left.F_{(6,57)}=3.09 ; p=0.3744\right]$. In particular, HVC and RA volumes of males were significantly larger than those of females throughout all studied time-points (Figures 5A,C; Tables 1A,B for $p$-values of all post-hoc pairwise-comparisons between the sexes).

In males, HVC volumes of $20 \mathrm{dph}$ birds were significantly smaller than those of all other age classes, except the $30 \mathrm{dph}$ birds (Figure 5A; Table 1A for $p$-values of all post-hoc pairwisecomparisons between age-groups reported below). Further, from one studied developmental time-point to the next only the HVC size of 30 to $50 \mathrm{dph}$ differed significantly. In females, HVC volumes of $20 \mathrm{dph}$ were significantly smaller than those of 50,100, and $150 \mathrm{dph}$ birds but similar to those of $250 \mathrm{dph}$ and adults. Only $100 \mathrm{dph}$ females had significantly larger HVCs than adults. In summary, male HVC increased in volume till $50 \mathrm{dph}$ and decreased again toward adulthood. In females, HVC increased in volume from 30 to $100 \mathrm{dph}$ and decreased significantly afterwards so that HVCs of older $(250 \mathrm{dph}$ and 
adults) females were similar in size to those of very young females.

Likewise, RA volumes of males and females changed during development (Figure 5C; see Table 1B for $p$-values of all post-hoc pair-wise comparisons between age groups reported below). For

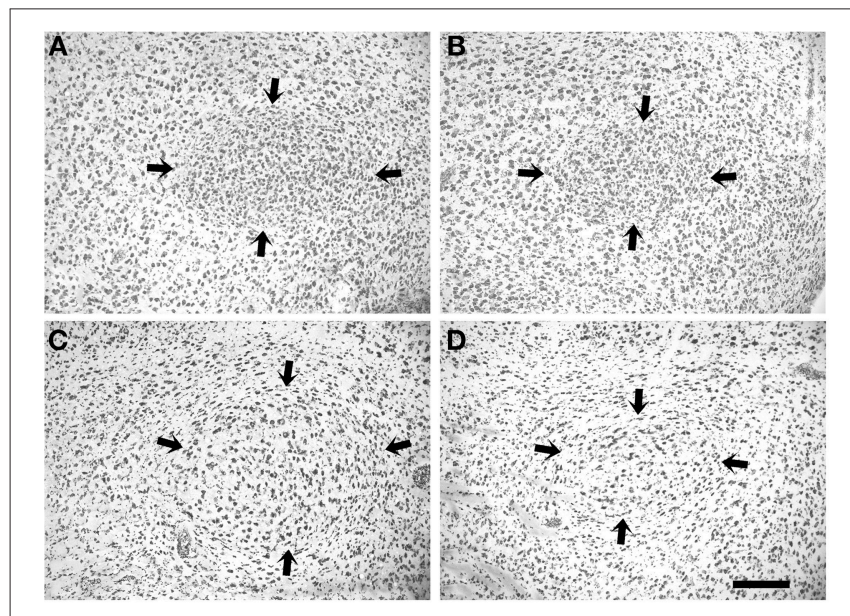

FIGURE 4 | Nissl-stainings of RA (arrows) of a 20-day male (A), an adult male (C), a 20-day female (B), and an adult female (D) blue-capped cordon bleu. Scale bar is $100 \mu \mathrm{m}$. the males, the RAs at $20 \mathrm{dph}$ were significantly smaller than those of all older birds. From one developmental time-point to the next, the RA volume increased significantly from 20 to 30 and from 50 to $100 \mathrm{dph}$ and decreased significantly from 100 to adulthood. In females, RA volumes increase significantly till 100 and $150 \mathrm{dph}$ and then decreased till adulthood although this was only significant between $100 \mathrm{dph}$ and adulthood. At the developmental peak of $100 \mathrm{dph}$, the RA volumes of males were significantly larger compared to all other time-points, the RA volumes of females were significantly larger than those of 20, 30, $50 \mathrm{dph}$ and adult females.

The degrees of sexual dimorphism (female to male ratio of mean volumes) of HVC and RA fluctuated between 0.7 and 0.5 during lifespan.

\section{Development of HVC and RA Neuron Numbers}

To further study the sexual dimorphism and development of HVC and RA we analyzed the neuron numbers of 20,100 dph, and adult females and males (Figures 5B,D, 6, Table 2). Neuron numbers of male and female HVCs $\left[F_{(5,24)}=34.54, p<0.0001\right]$ changed during ontogeny with an effect of age $\left[F_{(2,24)}=53\right.$. $40, p<0.0001]$ and of $\operatorname{sex}\left[F_{(1,24)}=14.53, p=0.0008\right]$ but no interaction between sex and age $\left[F_{(2,24)}=1.33, p=\right.$ 0.28] (Figure 5B, Table 2A for $p$-values of pair-wise comparisons

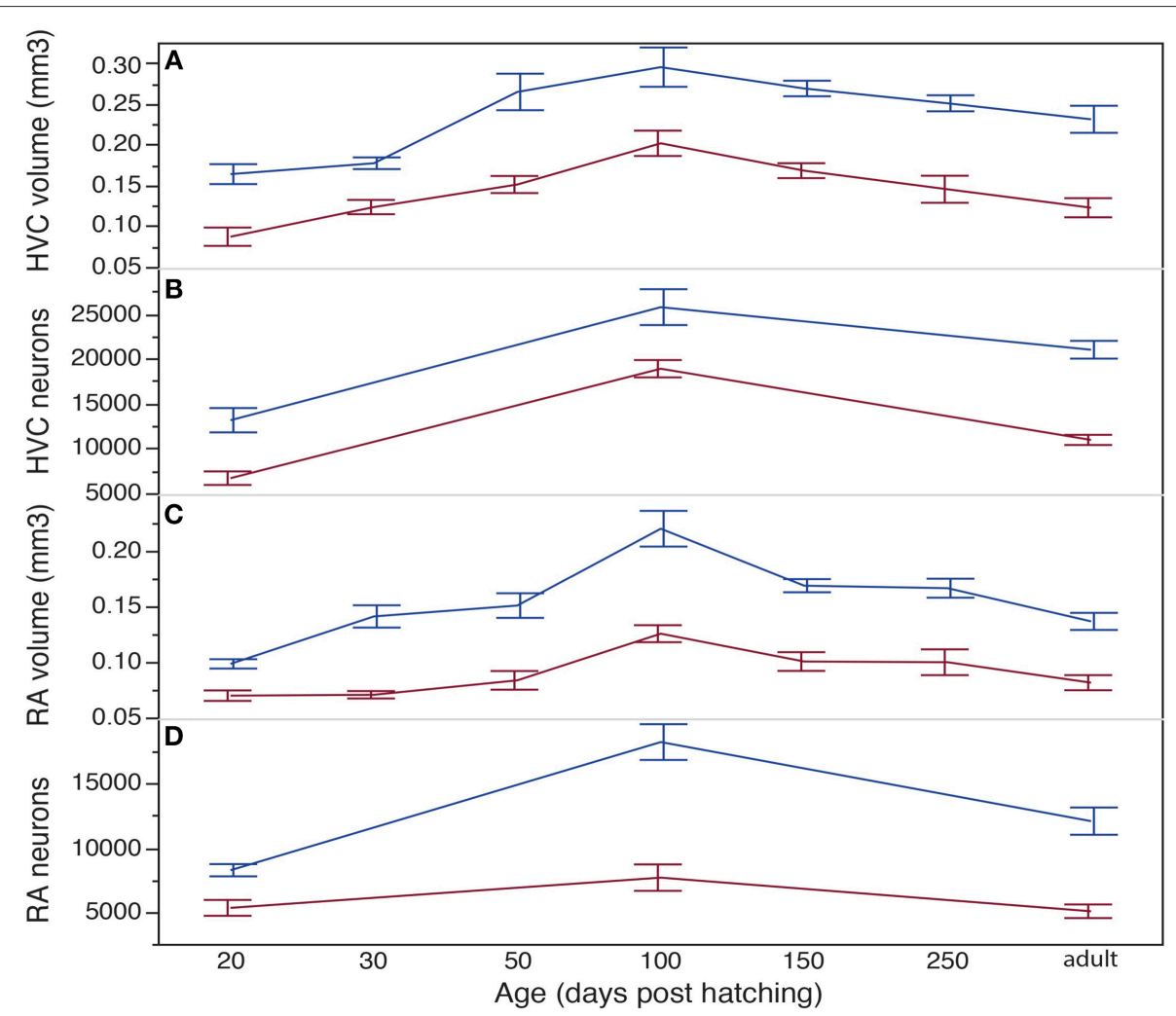

FIGURE 5 | The development of the HVC volume (A), HVC neuron numbers (B), RA volume (C), and RA neuron numbers (D) of female (red lines) and male (blue lines) blue-capped cordon-bleus. HVC and RA volumes and neuron numbers are sexually dimorphic throughout ontogeny and in adulthood. For the statistics of intra-sex comparisons see Tables 1, 2. Note the difference in scale between A and C, B and D. Data are presented as mean \pm 1 SE. 
TABLE 1 | Comparisons of HVC (A) and RA (B) volumes of females and males revealed by Tukey post-hoc tests.

\begin{tabular}{|c|c|c|c|c|c|c|c|}
\hline Age & $20 \mathrm{dph}$ & $30 \mathrm{dph}$ & $50 \mathrm{dph}$ & $100 \mathrm{dph}$ & $150 \mathrm{dph}$ & $250 \mathrm{dph}$ & Adult \\
\hline \multicolumn{8}{|c|}{ (A) HVC VOLUMES } \\
\hline $20 \mathrm{dph}$ & 0.001 & 0.325 & 0.009 & 0.0001 & 0.001 & 0.070 & 0.259 \\
\hline $0 \mathrm{dph}$ & 0.997 & $<0.0001$ & 0.679 & 0.002 & 0.218 & 0.923 & 1.00 \\
\hline $50 \mathrm{dph}$ & 0.003 & 0.017 & 0.002 & 0.084 & 0.964 & 1.00 & 0.567 \\
\hline 100 dph & 0.0001 & 0.001 & 0.861 & 0.012 & 0.537 & 0.104 & 0.001 \\
\hline 150 dph & 0.003 & 0.018 & 1.00 & 0.943 & $<0.0001$ & 0.924 & 0.145 \\
\hline $250 \mathrm{dph}$ & 0.043 & 0.149 & 0.999 & 0.684 & 0.995 & 0.005 & 0.886 \\
\hline Adult & 0.049 & 0.227 & 0.738 & 0.095 & 0.691 & 0.988 & $<0.000$ \\
\hline \multicolumn{8}{|c|}{ (B) RA VOLUMES } \\
\hline $20 \mathrm{dph}$ & 0.001 & 1.0 & 0.686 & 0.0001 & 0.050 & 0.107 & 0.749 \\
\hline $30 \mathrm{dph}$ & 0.0004 & $<0.0001$ & 0.846 & 0.001 & & 0.195 & 0.900 \\
\hline $50 \mathrm{dph}$ & 0.0001 & 0.987 & 0.001 & 0.018 & 0.703 & 0.810 & 1.00 \\
\hline $100 \mathrm{dph}$ & 0.0001 & 0.0001 & 0.003 & 0.001 & 0.545 & 0.599 & 0.005 \\
\hline $150 \mathrm{dph}$ & 0.0001 & 0.436 & 0.851 & 0.124 & 0.001 & 1.00 & 0.497 \\
\hline $250 \mathrm{dph}$ & 0.0001 & 0.622 & 0.939 & 0.146 & 1.00 & 0.01 & 0.648 \\
\hline Adult & 0.005 & 1.00 & 0.887 & 0.0001 & 0.196 & 0.365 & $<0.0001$ \\
\hline
\end{tabular}

$P$-values of female-female comparisons are in light-gray, those of male-male comparisons in dark-gray, and those of male-female comparisons are in the diagonal. Significant $P$-values are in bold. dph, age in days post-hatching.

between time-points reported below). In both sexes, neuron numbers increased significantly between 20 and $100 \mathrm{dph}$ and dropped significantly between $100 \mathrm{dph}$ and adulthood, so that adult HVC neuron numbers differed from those of $20 \mathrm{dph}$ birds. Similar, in RA, neuron numbers changed during development $\left[F_{(5,18)}=21.74, p<0.0001\right]$ with an effect of age $\left[F_{(2,18)}=\right.$ 15.59, $p=0.0001]$ and $\operatorname{sex}\left[F_{(1,18)}=12.62, p=0.0023\right]$ but without interaction between age and $\operatorname{sex}\left[F_{(2,18)}=3.1\right.$, $p=0.07$ ] (Figure 5D, Table 2B for $p$-values of pair-wise comparisons between time-points reported below). Hence, the peak in neuron numbers at $100 \mathrm{dph}$ of males and females was significant. RA neuron numbers dropped significantly after $100 \mathrm{dph}$ till adulthood so that neuron numbers of adult females but not of adult males were similar to neuron numbers of $20 \mathrm{dph}$ juveniles (Figure 5D, Table 2B). Further, neuron numbers of 20-, 100-day, and adult HVC and RA were significantly higher in males than females (Figures 5B,D; $p<0.0025$ in all cases [Tables 2A,B]).

\section{DISCUSSION}

\section{Sexually Dimorphic Development of HVC and RA does not Correlate with Sex-specific Song Development}

Blue-capped cordon-blues are representative of many tropical and sub-tropical songbird species in which females sing regularly throughout life and sing a species-typical song pattern that is as well produced by their male conspecifics (for review: Odom et al., 2014). Thus, this species is a perfect model to study song and song system development of both males and females in contrast to the zebra finch, in which only the male is singing and in which song control areas are rudimentary in females (Nottebohm and Arnold, 1976). Nevertheless, volume and neuron numbers of forebrain song control regions HVC and RA that are crucial for song development and production are sexually dimorphic in adult blue-capped cordon-bleus, about 55 and $40 \%$ smaller, respectively, in females as compared to the males consisting of about $50 \%$ less neurons. Since, song patterns of adults (considering song duration and syllable repertoire size) are sexually dimorphic (this study; Geberzahn and Gahr, 2011), one might suggest a positive correlation between the neuroanatomy of the song system and sex differences in song. If this assumption were correct, blue-capped cordon-bleus would be similar to a group of species such as various wrens (e.g., Brenowitz et al., 1985; Brenowitz and Arnold, 1986; DeVoogd et al., 1988), Northern cardinals (Cardinalis cardinalis; Jawor and MacDougall-Shackleton, 2008; Yamaguchi, 1998), and starlings (Sturnus vulgaris; Bernard et al., 1993; Hausberger et al., 1995) in which small to medium sex differences in song pattern correlate with small to medium sex differences in the morphology of the song system. Sex-specific singing activity as the behavioral correlate of the observed neuroanatomical differences between male and female blue-capped cordon-bleus is unlikely since both sexes are able to sing equally frequently after removal of their mate (Geberzahn and Gahr, personal observation). Further, works in streak-backed oriol (Icterus pustulatus) showed that there is male-based sex difference in HVC morphology although females out-sing males in this species (Illes and YunesJimenez, 2009; Hall et al., 2010). In the following, we discuss the relation of song development and song system development of males and females in order to validate the adult sexual dimorphisms.

Most surprisingly, during development, (1) the sex difference in the song system anatomy precedes the onset of song production and (2) song development progresses in a monomorphic way while the sexual neuroanatomical dimorphism is evident throughout the ontogeny (HVC and RA are $30-50 \%$ smaller in females than in males; Figures 5A,C) of the song system. The sex-specific vocal features (syllable repertoire, song duration) emerged only in adulthood. Thus, the main explanatory challenge of the present data concerns that female cordon-bleus develop their songs (that are comparable with those of males) with much less (ca. 30-50\% less HVC and ca. 35-55\% less RA) neurons than their male conspecifics. Either HVC and RA neuron numbers are the limiting factor for song development only in cases (females of certain species) in which song neuron numbers are below a certain threshold such as in the female zebra finch (Konishi and Akutagawa, 1985) and female Bengalese finches (Lonchura striata var. domestica) (Tobari et al., 2005; Gahr, unpublished observation), or female cordon-bleus differentiate song control circuits that differ qualitatively from those of their male conspecifics. In the first case, HVC and RA neuron numbers would be overproduced in case of the males, which leads to the question of evolutionary stability of this trait in light of developmental costs (Gil and Gahr, 2002). However, the regression of the size of HVC and RA neuron pools in the females of species in which females do not sing makes this conclusion unlikely. 

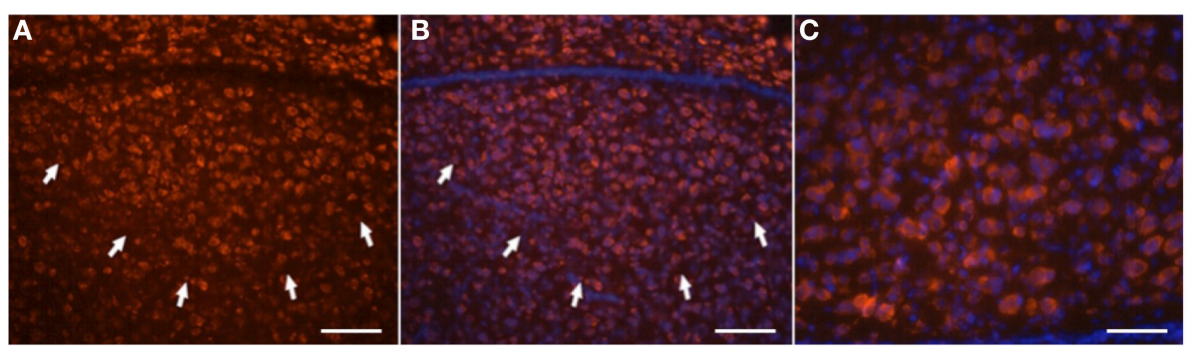

FIGURE 6 | Neuron-specific $\left(\mathbf{H u}^{+}\right.$) labeling of HVC neurons. Hu-antibody labeling is red (A), cell nucleus (Dapi) labeling is blue (B,C). Double-labeled cells are identified as neurons (B,C). (C) Shows a higher magnification view of (B). Arrows indicate the ventral borders of HVC. Scale bar is $100 \mu \mathrm{m}$ in $\mathrm{A}$ and $\mathrm{B}$, and $40 \mu \mathrm{m}$ in $\mathbf{C}$.

TABLE 2 | Comparisons of HVC (A) and RA (B) neuron numbers of females and males revealed by Tukey post-hoc tests.

\begin{tabular}{|c|c|c|c|}
\hline Age & $20 \mathrm{dph}$ & 100 dph & Adult \\
\hline \multicolumn{4}{|c|}{ (A) HVC NEURON NUMBERS } \\
\hline 20 dph & 0.0008 & $<0.001$ & 0.0189 \\
\hline 100 dph & $<0.0001$ & 0.0005 & $<0.0001$ \\
\hline Adult & $<0.0001$ & 0.01 & $<0.0001$ \\
\hline \multicolumn{4}{|c|}{ (B) RA NEURON NUMBERS } \\
\hline 20 dph & 0.0023 & 0.0221 & 0.7640 \\
\hline 100 dph & $<0.0001$ & 0.0005 & 0.0159 \\
\hline Adult & 0.0132 & 0.0147 & $<0.001$ \\
\hline
\end{tabular}

$P$-values of female-female comparisons are in light-gray, those of male-male comparisons in dark-gray, and those of male-female comparisons are in the diagonal. Significant $P$-values are in bold. dph, age in days post-hatching.

Further (see below), both male and female cordon-bleus regulate the size of the HVC neuron pool during development (Figures 5B,D). Likewise, in species in which adult males and females sing identical songs (Gahr et al., 2008) or very similar songs (Gahr et al., 1998; Schwabl et al., 2015) or in which females and subordinate males sing the same song (Voigt and Gahr, 2011), there is nevertheless a strong sex difference of the song system anatomy. As the most parsimonious explanation we suggest that female cordon-bleus evolved HVC and RA circuits that function differently from those of the males to compensate for smaller song neuron pools in order to allow sensorimotor learning and the production of learned songs. Additional male-specific functions of HVC and RA next to singing are currently unknown. For example, the control of call exchanges by forebrain song areas (Ter Maat et al., 2014) is not male-specific (Trost et al., unpublished data), and therefore cannot account for the observed differences in HVC and RA anatomy.

\section{Developmental Mechanisms of HVC and RA Size}

Early sex difference in the number of song neurons preceding the onset of song production might be a general feature of estrildid finches (family Estrildidae) but not typical for other songbirds. However, since it occurs as well in juvenile canaries (Gahr et al., 1997), a species of the carduelid genus (family Fringillidae), early ontogenetic sex difference of the song system is likely an ancestral general songbird feature, due to the evolutionary history of the songbird suborder, as suggested previously (Gahr et al., 2008; Schwabl et al., 2015). In relation, sexually dimorphic song control areas were found in all species studied in detail (significant number of individuals) of various families of both the Passerida lineage (e.g., Estrildidae: zebra finch, Nottebohm and Arnold, 1976; Troglodytidae: bay wren, Thryothorus nigricapillus, (Brenowitz and Arnold, 1986); Ploceidae: forest weaver, Ploceus bicolor, Gahr et al., 2008); and the Corvida lineage (e.g., Corvidae: large-billed crows, Corvus macrorhynchos, Wang et al., 2009; Malaconotidae: slate-colored boubou, Laniarius funebris, Gahr et al., 1998; Icteridae: streak-backed oriole, Icterus pustulatus, Hall et al., 2010) of oscines as well as in the red-backed fairy wren (Malurus melanocephalus, Schwabl et al., 2015) of the basal oscine family Maluridae, according to the oscine phylogeny of Barker et al. (2004). However, the study of sex differences of the developing song system of further species with singing females, in particular of the basal australo-asian oscine lineages would be desirable.

Initial sex differences in the size of HVC and RA neuron pools of zebra finches are likely genetically determined (Wade and Arnold, 1996; Gahr et al., 1998; Agate et al., 2003) suggesting a similar explanation for the early sex differences of cordonbleu song areas. The subsequent ontogenetic development of the song system might be linked to gonadal hormone activity although clear proof for this is missing in any songbird species except for the observation that androgen receptors are expressed in the developing HVC and RA (Gahr, 1996; Gahr and Metzdorf, 1999; Jacobs et al., 1999; Kim et al., 2004) and that estrogen receptors occur in the juvenile HVC (Gahr and Konishi, 1988; Gahr, 1996). Gonadal hormones are likely to promote the survival of song neurons to a developmental stage that allows the intra-song system connectivity to form, which is thought necessary for song learning and development. Further, song system development of zebra finches, starlings, and canaries is sensitive to pharmacological levels of testosterone and its estrogenic metabolite $17 \beta$-estradiol (Gurney and Konishi, 1980; Gurney, 1981; Weichel et al., 1989; Casto and Ball, 1996). Since the overall development of HVC and RA of male and female blue-capped cordon-bleu females was very similar (Figures 5A,C), similar mechanisms are likely to stimulate the increase and decrease in size of these brain 
areas during ontogenetic stages of males and females. It is, however, unlikely that the developing ovary would secret elevated testosterone levels, which in turn could facilitate song system differentiation of the females. For e.g., at $100 \mathrm{dph}$, HVC of female cordon bleus reached a size similar to that of adult males. Thus, the mechanisms controlling the developing song system of females (and males) need further investigations.

On the cellular level, changes of HVC and RA volume might be due to a combination of different forms of plasticity: neurogenesis, gliogenesis, dendritic sprouting, myelination, vascularization, synapse forming, pruning (synaptic, axonal), cell death (neurons, glia, endothelial cells), and regression (dendrites, vessels, glia) (for review: Stiles and Jernigan, 2010; Anderson, 2011). Of these, we estimated neuron numbers as a factor underlying developmental volumetric changes of HVC and RA of male and female cordon-bleus. The increase of HVC volume from 20 to $100 \mathrm{dph}$ involved a strong increase in neuron numbers. In relation, protracted neurogenesis is a general event of the postnatal birdbrain (males and females) and recruitment of considerable numbers of new HVC neurons has been demonstrated during development of the HVC of male zebra finch (Kirn and DeVoogd, 1989; Kirn, 2010). Although only shown for males, it is conceivable that recruitment of newly born neurons occurs in both male and female HVC during post-hatching life, next to spreading out of early born HVC neurons (Gahr and Metzdorf, 1999). After $100 \mathrm{dph}$, the decline of HVC size of the females correlates with the reduction of HVC neuron numbers (Figures 5A,B), however, in males, HVC neuron numbers decline without changes of HVC size (Figures 5C,D).

In case of RA, there is a correlation between neuron number development and volume development in males and females. In zebra finches, most RA neurons are born before/around hatching and post-hatching neurogenesis seems to exclude the arcopallium (in which RA forms) of songbirds (Konishi and Akutagawa, 1990; Vellema et al., 2010). Since neuron numbers of cordon-bleus' RA increased after $20 \mathrm{dph}$, a large number of these neurons must be born much later as compared to the zebra finch, which might be plausible in light of the much longer ontogeny of the cordonbleus (this study) as compared to the zebra finch (Immelmann, 1969; Konishi and Akutagawa, 1988). Alternatively, early born neurons might differentiate into RA neurons at a late time point. Thus, we need to consider that delineation problems of the brain areas (Gahr, 1990, 1997), i.e., the recognition of the outlines of $\mathrm{RA}$ (as well as of HVC for this argument) might have considerable effects on the estimated neuron numbers particularly in very young males and females.

However, future studies are needed to monitor various forms of plasticity, in particular neurogenesis and apoptosis, dendritic arborization, and gliogenesis, to confirm and extend the above considerations explaining the developmental change of HVC and RA volume of female and male blue-capped cordon-bleus. A future detailed study of the hormonal profiles of developing male and female cordon-bleus might show if gonadal hormones are important for sex-specific development of the song system in this species.

\section{What are the Behavioral Consequences of the Increase and Decrease of HVC and RA Volume, Respectively Neuron Numbers of Male and Female Blue-capped Cordon-bleus?}

Since we suggested above that the HVC and RA circuits of males and females function in a sex-specific way, we do not consider sexual dimorphisms in volume and neuron numbers for this discussion, i.e., we focus on the relationship of developmental changes of brain and song behavior. In either sex, the increase of volume of HVC and RA between 20 and $100 \mathrm{dph}$ (and of HVC neuron numbers) might correlate with a reduced variability in singing that is reflected in recurring syllables, i.e., a measurable syllable repertoire at $100 \mathrm{dph}$ (Figures 1, 2A,B, 5). Further, around this age the animals might produce the largest number of different syllable sequences although this could not be quantified due to insufficient syllable stereotypy earlier on. Thus, the increase of HVC and RA size till $100 \mathrm{dph}$ might correlate with the production of an increased number of motor patterns. Although these syllables have a level of stereotypy that allows their classification, this stereotypy is certainly lower compared to songs uttered by older females and males (Figures 1, 2C). Between $100 \mathrm{dph}$ and adulthood syllable numbers decrease in both sexes, the stereotypy of syllable harmonicity increases in both sexes, and song duration decreases in females. We could view these song developments as increased stereotypy and decreased number of motor pattern that emerges in relation with decreasing HVC volumes (females) and RA volumes (males and females) of cordon-bleus. Further, increased stereotypy and decreased number of motor pattern would correlate with decreasing numbers of neurons of HVC and RA after 100. A decreasing rate of adult neurogenesis and newly recruited HVC neurons was thought to correlate with increasing stereotypy of the song of male zebra finches (Pytte et al., 2007).

A relationship of the anatomical development of forebrain song control areas and of song learning has been hypothesized before based on male zebra finches and male canaries (for review: Kirn, 2010). However, as detailed above, in the cordon-bleus a causal relationship between anatomical changes of HVC and RA and song development would be area- and sex-specific. Alternatively, such complicated relationships might indicate that-like in human brain and cognitive development (Stiles and Jernigan, 2010) - the maturation and deterioration of specific brain regions is an insufficient explanatory mechanism for song development of birds. Further, late developmental changes of the syllable repertoire in female cordon-bleus show that females do not just lose syllables but seem to acquire new syllables and replace old ones at late puberty/early adulthood (Figure 1). Likewise, male cordon-bleus change their repertoire very late (after $250 \mathrm{dph}$ ) at an age when the size of vocal areas already reached adult size. Thus, sexual selection or the need for social song adjustment rather than brain autonomous maturation processes might play a role for the decrease in repertoire size and song duration in female cordon-bleus and for the change of repertoire composition in both males and females, independent of gross morphological changes. On more ultimate 
terms, developmental overproduction of song patterns followed by repertoire attrition has been described for several species and has been interpreted in the context of social adjustments of repertoires (e.g., Marler and Peters, 1982; Nelson, 1992; Geberzahn et al., 2002). Future long-term monitoring of cordonbleus shall show if females and males of this species classify as open-ended vocal learners in contrast to other Estrildid finches such as the zebra finch.

\section{CONCLUSION}

In summary, the comparative study of song system development and song development of the blue-capped cordon-bleus, a species in which males and females sing learned songs sheds new light on the potential relationships between these processes. In particular,

\section{REFERENCES}

Agate, R. J., Grisham, W., Wade, J., Mann, S., Wingfield, J., Schanen, C., et al. (2003). Neural, not gonadal, origin of brain sex differences in a gynandromorphic finch. Proc. Natl. Acad. Sci. U.S.A. 100, 4873-4878. doi: 10.1073/pnas.0636925100

Amador, A., Perl, Y. S., Mindlin, G. B., and Margoliash, D. (2013). Elemental gesture dynamics are encoded by song premotor cortical neurons. Nature 495, 59-64. doi: 10.1038/nature11967

Anderson, B. J. (2011). Plasticity of grey matter volume: the cellular and synaptic plasticity that underlies volumetric change. Dev. Psychobiol. 53, 456-465. doi: $10.1002 / \mathrm{dev} .20563$

Barami, K., Iversen, K., Furneaux, H., and Goldman, S. A. (1995). Hu protein as an early marker of neuronal phenotypic differentiation by subependymal zone cells of the adult songbird forebrain. J. Neurobiol. 28, 82-101. doi: $10.1002 /$ neu. 480280108

Barker, F. K., Cibois, A., Schikler, P., Feinstein, J., and Cracraft, J. (2004). Phylogeny and diversification of the largest avian radiation. Proc. Natl. Acad. Sci. U.S.A. 101, 11040-11045. doi: 10.1073/pnas.0401892101

Beletsky, L. D. (1983). Aggressive and pair-bond maintenance songs of female red-winged blackbirds (Agelaius phoeniceus). Z. Tierpsychol. 62, 47-54

Bernard, D. J., Casto, J. M., and Ball, G. F. (1993). Sexual dimorphism in the volume of song control nuclei in European starlings: assessment by a Nissl stain and autoradiography for muscarinic cholinergic receptors. J. Comp. Neurol. 334, 559-570. doi: 10.1002/cne.903340405

Brenowitz, E. A., and Arnold, A. P. (1986). Interspecific comparisons of the size of neural song control regions and song complexity in duetting birds: evolutionary implications. J. Neurosci. 6, 2875-2879.

Brenowitz, E. A., Arnold, A. P., and Levin, R. N. (1985). Neural correlates of female song in tropical duetting birds. Brain Res. 343, 104-112. doi: 10.1016/00068993(85)91163-1

Casto, J. M., and Ball, G. F. (1996). Early administration of 17beta-estradiol partially masculinizes song control regions and alpha2-adrenergic receptor distribution in European starlings (Sturnus vulgaris). Horm. Behav. 30, 387-406. doi: 10.1006/hbeh.1996.0044

DeVoogd, T. J., Brenowitz, E. A., and Arnold, A. P. (1988). Small sex differences in song control dendrites are associated with minimal differences in song capacity. J. Neurobiol. 19, 199-209. doi: 10.1002/neu.480190303

DeVoogd, T. J., Krebs, J. R., Healy, S. D., and Purvis, A. (1993). Relations between song repertoire size and the volume of brain nuclei related to song: comparative evolutionary analyses amongst oscine birds. Proc. R Soc. Lond. B Biol. Sci. 254, 75-82. doi: 10.1098/rspb.1993.0129

DeVoogd, T. J., and Nottebohm, F. (1981). Sex differences in dendritic morphology of song control nucleus in the canary: a quantitative Golgi-study. J. Comp. Neurol. 196, 309-316. doi: 10.1002/cne.901960209

Gahr, M. (1990). Delineation of a brain nucleus: comparison of cytochemical, hodological, and cytoarchitectural views of the song control nucleus HVC of the adult canary. J. Comp. Neurol. 294, 30-36. doi: 10.1002/cne.902940104

Gahr, M. (1996). Developmental changes in the distribution of oestrogen receptor mRNA expressing cells in the forebrain of female, male and masculinized sex-specific song system development seems not strictly related to sex-specific song development. This suggests that medium to small sex differences in the phenotype of the song system are not predictive concerning the degree of song monomorphy of songbirds. The study of further species in which males and females sing very similar songs (Odom et al., 2014) should show if the dissociation of neuroanatomical and song development is a general feature of songbirds.

\section{ACKNOWLEDGMENTS}

We thank M.L. Hall and N.E. Langmore for inviting us to contribute to this special issue. We thank Dr. Andries ter Maat for statistical advice and David Witkowski for maintaining the blue-capped cordon-bleu colony at Seewiesen.

female zebra finches. Neuroreport 7, 2469-2473. doi: 10.1097/00001756199611040-00013

Gahr, M. (1997). How should brain nuclei be delineated? Consequences for developmental mechanisms and for correlations of area size, neuron numbers and functions of brain nuclei. Trends Neurosci. 20, 58-62. doi: 10.1016/S01662236(96)10076-X

Gahr, M. (2014). How hormone sensitive is bird song, and what are the underlying mechanisms. Acta Acust. 100, 705-718. doi: 10.3813/AAA.918749

Gahr, M., and Güttinger, H. R. (1985). Korrelation zwischen der sexualdimorphen Gehirndifferenzierung und der Verhaltensausprägung bei Prachtfinken (Estrildidae). J. Ornithol. 126, 310. doi: 10.1007/BF01640376

Gahr, M., and Konishi, M. (1988). Developmental changes in estrogen-sensitive neurons in the forebrain of the zebra finch. Proc. Natl. Acad. Sci. U.S.A. 85, 7380-7383. doi: 10.1073/pnas.85.19.7380

Gahr, M., and Metzdorf, R. (1999). The sexually dimorphic expression of androgen receptors in the song nucleus hyperstriatalis ventrale pars caudale of the zebra finch develops independently of gonadal steroids. J. Neurosci. 19, 2628-2636.

Gahr, M., Metzdorf, R., and Aschenbrenner, S. (1997). The ontogeny of the canary HVC revealed by the expression of androgen and estrogen receptors. Neuroreport 8, 311-315.

Gahr, M., Metzdorf, R., Schmidl, D., and Wickler, W. (2008). Bi-directional sexual dimorphisms of the song control nucleus HVC in a songbird with unison song. PLoS ONE 3:e3073. doi: 10.1371/journal.pone.0003073

Gahr, M., Sonnenschein, E., and Wickler, W. (1998). Sex differences in the size of the neural song control regions in a dueting songbird with similar song repertoire size of males and females. J. Neurosci. 18, 1124-1131.

Garamszegi, L. Z., Pavlova, D. Z., Eens, M., and Moller, A. P. (2006). The evolution of song in female birds in Europe. Behav. Ecol. 18, 86-96 doi: 10.1093/beheco/arl047

Geberzahn, N., and Gahr, M. (2011). Undirected (Solitary) birdsong in female and male blue-capped cordon-bleus (Uraeginthus cyanocephalus) and its endocrine correlates. PLoS ONE 6:e26485. doi: 10.1371/journal.pone.0026485

Geberzahn, N., and Gahr, M. (2013). Song learning in male and female Uraeginthus cyanocephalus, a tropical songbird species. J. Comp. Psychol. 127, 352-364. doi: $10.1037 / \mathrm{a} 0033154$

Geberzahn, N., and Hultsch, H. (2003). Long-time storage of song types in birds: evidence from interactive playbacks. Proc. R. Soc. Lond. B. Biol. Sci. 270, 1085-1090. doi: 10.1098/rspb.2003.2340

Geberzahn, N., Hultsch, H., and Todt, D. (2002). Latent song type memories are accessible through auditory stimulation in a hand-reared songbird. Anim. Behav. 64, 783-790. doi: 10.1006/anbe.2002.3099

Gil, D., and Gahr, M. (2002). The honesty of bird song: multiple constraints for multiple traits. Trends Ecol. Evol. 17, 133-141. doi: 10.1016/S01695347(02)02410-2

Gurney, M. E. (1981). Hormonal control of cell form and number in the zebra finch song system. J. Neurosci. 1, 658-673.

Gurney, M. E., and Konishi, M. (1980). Hormone-induced sexual-differentiation of brain and behavior in zebra finches. Science 208, 1380-1383. doi: $10.1126 /$ science. 208.4450 .1380 
Hahnloser, R. H., Kozhevnikov, A. A., and Fee, M. S. (2002). An ultra-sparse code underlies the generation of neural sequences in a songbird. Nature 419, 65-70. doi: 10.1038 /nature00974

Hall, Z. J., MacDougall-Shackleton, S. A., Osorio-Beristain, M., and Murphy, T. G. (2010). Male bias in the song control system despite female bias in song rate in streak-backed oriols (Icterus pustulatus). Brain Behav. Evol. 76, 168-175. doi: 10.1159/000320971

Hartley, R. S., and Suthers, R. A. (1990). Lateralization of syringeal function during song production in the canary. J. Neurobiol. 21, 1236-1248. doi: 10.1002/neu.480210808

Hartog, T. E., Dittrich, F., Pieneman, A. W., Jansen, R. F., Frankl-Vilches, C., Lessmann, V., et al. (2009). BDNF signaling in the HVC is required for testosterone-induced song of female canaries. J. Neurosci. 29, 15511-15519 doi: 10.1523/JNEUROSCI.2564-09.2009

Hausberger, M., Richard-Yris, M. A., Henry, L., Lepage, L., and Schmidt, I. (1995). Song sharing reflects the social organization in a captice group of European starlings (Sturnus vulgaris). J. Comp. Psychol. 109, 222-241. doi: 10.1037/07357036.109.3.222

Hoelzel, A. R. (1986). Song characteristics and response to playback of male and female Robins Erithacus rubecula. Ibis 128, 115-127. doi: 10.1111/j.1474919X.1986.tb02098.x

Holloway, C. C., and Clayton, D. F. (2001). Estrogen synthesis in the male brain triggers development of the avian song control pathway in vitro. Nat. Neurosci. 4, 170-175. doi: 10.1038/84001

Illes, A. E., and Yunes-Jimenez, L. (2009). A female songbird out-sings male conspecifics during simulated territorial intrusions. Proc. Biol. Sci. 276, 981-986. doi: 10.1098/rspb.2008.1445

Immelmann, K. (1969). "Song development in the zebra finch and other estrildid finches," in Bird Vocalizations, ed R. A. Hinde (Cambridge: Cambridge University Press), 64-74.

Jacobs, E. C., Arnold, A. P., and Campagnoni, A. T. (1999). Developmental regulation of the distribution of aromatase- and estrogen-receptor-mRNAexpressing cells in the zebra finch brain. Dev. Neurosci. 21, 453-472.

Jawor, J. M., and MacDougall-Shackleton, S. A. (2008). Seasonal and sex-related variation in song control nuclei in a species with nearmonomorphic song, the northern cardinal. Neurosci. Lett. 443, 169-173. doi: 10.1016/j.neulet.2008.07.085

Kim, Y. H., Perlman, W. R., and Arnold, A. P. (2004). Expression of androgen receptor mRNA in zebra finch song system: developmental regulation by estrogen. J. Comp. Neurol. 469, 535-547. doi: 10.1002/cne.11033

Kirn, J. R. (2010). The relationship of neurogenesis and growth of brain regions to song learning. Brain Lang. 115, 29-44. doi: 10.1016/j.bandl.2009.09.006

Kirn, J. R., and DeVoogd, T. J. (1989). Genesis and death of vocal control neurons during sexual differentiation in the zebra finch. J. Neurosci. 9, 3176-3187.

Konishi, M., and Akutagawa, E. (1985). Neuronal growth, atrophy and death in a sexually dimorphic song nucleus in the zebra finch brain. Nature 315, 145-147. doi: $10.1038 / 315145 \mathrm{a} 0$

Konishi, M., and Akutagawa, E. (1988). A critical period for estrogen action on neurons of the song control system of the zebra finch. Proc. Natl. Acad. Sci. U.S.A. 85, 7006-7007. doi: 10.1073/pnas.85.18.7006

Konishi, M., and Akutagawa, E. (1990). Growth and atrophy of neurons labeled at their birth in a song nucleus of the zebra finch. Proc. Natl. Acad. Sci. U.S.A. 87, 3538-3541. doi: 10.1073/pnas.87.9.3538

Langmore, N. E., Davies, N. B., Hatchwell, B. J., and Hartley, I. R. (1996). Female song attracts males in the alpine accentor Prunella collaris. Proc. R. Soc. Lond. B 263, 141-146. doi: 10.1098/rspb.1996.0022

Leitner, S., Voigt, C., and Gahr, M. (2001). Seasonal changes in the song pattern of the non-domesticated island canary (Serinus canaria), a field study. Behaviour 138, 885-904. doi: 10.1163/156853901753172700

MacDougall-Shackelton, S. A., and Ball, G. F. (1999). Comparative studies of sex differences in the song control system of songbirds. Trends Neurosci. 22, 432-436. doi: 10.1016/S0166-2236(99)01434-4

Marler, P., and Peters, S. (1982). Developmental overproduction and selective attrition: new processes in the epigenesis of birdsong. Dev. Psychobiol. 15, 369-378. doi: 10.1002/dev.420150409

Marusich, M. F., Furneaux, H. M., Henion, P. D., and Weston, J. A. (1994). Hu neuronal proteins are expressed in proliferating neurogenic cells. J. Neurobiol. 25, 143-155.

Nelson, D. A. (1992). Song overproduction and selective attrition lead to song sharing in the field sparrow (Spizella pusilla). Behav. Ecol. Sociobiol. 30, 415-424. doi: 10.1007/BF0 0176177

Nottebohm, F. (1980). Testosterone triggers growth of brain vocal control nuclei in adult female canaries. Brain Res. 189, 429-436. doi: 10.1016/00068993(80)90102-X

Nottebohm, F., and Arnold, A. P. (1976). Sexual dimorphism in vocal control areas of the songbird brain. Science 194, 211-213. doi: 10.1126/science.959852

Odom, K. J., Hall, M. L., Riebel, K., Omland, K. E., and Langmore, N. E. (2014). Female song is widespread and ancestral in songbirds. Nat. Commun. 5:3379. doi: $10.1038 /$ ncomms4379

Pesch, A., and Güttinger, H. R. (1985). Der Gesang des weiblichen Kanarienvogels. J. Ornithol. 126, 108-110. doi: 10.1007/BF01640450

Pytte, C. L., Gerson, M., Miller, J., and Kirn, J. R. (2007). Increasing stereotypy in adult zebra finch song correlates with a declining rate of adult neurogenesis. Dev. Neurobiol. 67, 1699-1720. doi: 10.1002/dneu.20520

Riebel, K., Hall, M. L., and Langemore, N. E. (2005). Female songbirds still struggling to be heard. Trends Ecol. Evol. 20, 419-420. doi: 10.1016/j.tree.2005.04.024

Schwabl, H., Dowling, J., Baldassarre, D. T., Gahr, M., Lindsay, W. R., and Webster, M. S. (2015). Variation in song system anatomy and androgen levels does not correspond to song characteristics in a tropical songbird. Anim. Behav. 104, 39-50. doi: 10.1016/j.anbehav.2015.03.006

Shoemaker, H. H. (1939). Effect of testosterone proprionate on behavior of the female canary. Proc. Soc. Exp. Biol. Med. 41, 299-302. doi: 10.3181/0037972741-10652

Slater, P. J. B., and Mann, N. I. (2004). Why do the females of many bird species sing in the tropics? J. Avian Biol. 35, 289-294. doi: 10.1111/j.0908-8857.2004.03392.x

Stiles, J., and Jernigan, T. L. (2010). The basics of brain development. Neuropsychol. Rev. 20, 327-348. doi: 10.1007/s11065-010-9148-4

Tchernichovski, O., Lints, T. J., Deregnaucourt, S., Cimenser, A., and Mitra, P. P. (2004). Studying the song development process: rationale and methods. Ann. N. Y. Acad. Sci. 1016, 348-363. doi: 10.1196/annals.1298.031

Ter Maat, A., Trost, L., Sagunsky, H., Seltmann, S., and Gahr, M. (2014). Zebra dinch mates use their forebrain song system in unlearned call communication. PLoS ONE 9:e109334. doi: 10.1371/journal.pone.0109334

Tobari, Y., Nakamura, K. Z., and Okanoya, K. (2005). Sex differences in the telencephalic song control cicuitry in Bengalese finches (Lonchura striata var. domestica). Zoolog. Sci. 22, 1089-1094. doi: 10.2108/zsj.22.1089

Vellema, M., van der Linden, A., and Gahr, M. (2010). Area-specific migration and recruitment of new neurons in the adult songbird brain. J. Comp. Neurol. 518, 1442-1459. doi: 10.1002/cne.22281

Voigt, C., and Gahr, M. (2011). Social status affects the degree of sex difference in the songbird brain. PLoS ONE 6:e20723. doi: 10.1371/journal.pone.0020723

Wade, J., and Arnold, A. P. (1996). Functional testicular tissue does not masculinize development of the zebra finch song system. Proc. Natl. Acad. Sci. U.S.A. 93, 5264-5268. doi: 10.1073/pnas.93.11.5264

Wang, R., Sun, Y., Zhang, X., Zeng, S., Xiw, W., Yu, Y., et al. (2009). Song control nuclei in male and female large-billed crows (Corvus macrorhynchos). Zool. Sci. 26, 771-777. doi: 10.2108/zsj.26.771

Weichel, K., Heid, P., and Güttinger, H. R. (1989). 17 $\beta$-Estradiolbenzoatedependent song induction in juvenile female canaries (Serinus canaria). Ethology 80, 55-70. doi: 10.1111/j.1439-0310.1989.tb00729.x

Yamaguchi, A. (1998). A sexually dimorphic learned birdsong in the Northern Cardinal. Condor 100, 504-511. doi: 10.2307/1369716

Yamaguchi, A. (2001). Sex differences in vocal learning birds. Nature 411, 257-258. doi: $10.1038 / 35077143$

Yu, A. C., and Margoliash, D. (1996). Temporal hierarchical control of singing in birds. Science 273, 1871-1875. doi: 10.1126/science.273.5283.1871

Conflict of Interest Statement: The authors declare that the research was conducted in the absence of any commercial or financial relationships that could be construed as a potential conflict of interest.

Copyright (c) 2015 Lobato, Vellema, Gahr, Leitão, de Lima, Geberzahn and Gahr. This is an open-access article distributed under the terms of the Creative Commons Attribution License (CC BY). The use, distribution or reproduction in other forums is permitted, provided the original author(s) or licensor are credited and that the original publication in this journal is cited, in accordance with accepted academic practice. No use, distribution or reproduction is permitted which does not comply with these terms. 